\title{
MY SOCIAL NETWORKING PROFILE: COPY, RESEMBLANCE, OR SIMULACRUM? A POSTRUCTURALIST INTERPRETATION OF SOCIAL INFORMATION SYSTEMS
}

\author{
Kreps, David, \\ Centre for Information Systems, Organisations and Society, University of Salford, The \\ Crescent, Salford, UK, d.g.kreps@salford.ac.uk
}

\begin{abstract}
This paper offers an introduction to poststructuralist interpretivist research in information systems, through a poststructuralist theoretical reading of the phenomenon and experience of social networking websites, like Facebook. This is undertaken through an exploration of how loyally a social networking profile can represent the essence of an individual, and whether Platonic notions of essence, and loyalty of copy, are disturbed by the nature of a social networking profile, in ways described by poststructuralist thinker Deleuze's notions of the reversal of Platonism. In bringing a poststructuralist critique to such hugely successful and popular social information systems, the paper attempts to further open up the black box of the computer 'user,' extend interpretive approaches to information systems research to embrace poststructuralism, and explore how notions of the Self might be reflected through engagement with IS, and how an IS appreciation of the phenomenon of global social networking may benefit from embracing such a poststructuralist approach.
\end{abstract}

Keywords: Poststructuralism, Interpretivism, Computer User, Cultural and Social, Human Computer Interaction, Human Factors, Societal Aspects of IS, Political and Social Implications 
"Artists, writers, and scientists do not hesitate in their creative efforts and researches to borrow ideas outside their own special fields," begins Philip P. Wiener, in his preface to the Dictionary of the History of Ideas (Wiener 1974). 'Intellectual history', as espoused by this and other later works, suggests that one must study the culture, lives and environments of people to understand their notions and ideas. In the spirit of such an intellectual history, this paper takes (and extends) an interpretivist approach to IS research into the 'users' of social networking sites. The aim of this paper, therefore, is not to present the results of any field research, nor to set out principles for such an endeavour (e.g. Klein \& Myers 1999). This paper addresses its subject matter from the vantage point of an intellectual historian. The aim is to introduce to the IS community a philosophical approach that the author believes to be both pertinent and appropriate to the subject matter, an extension of interpretivism (Walsham 1993, 1995) beyond the bounds of the organisation into the wider world of society at large, where today's information systems have indeed led, and to introduce to IS researchers a critical approach to the notion of identity that provides needed depth to our understanding of the global social networking phenomenon.

This approach, although innovative, has a good deal of pedigree in the IS literature. Walsham's introduction, in the early 1990s, of interpretivism into IS research, indeed heralds this new approach. As he states in his 1993 classic work, speaking of the designers and users of any information system, "Their interpretation of reality, their shared and contested sense of the world, create complex interacting contexts within which the information system, as a human artefact, is drawn on and used to create or reinforce meaning." (Walsham 1993:5) Importantly, Walsham points out that "In the interpretive tradition, there are no correct and incorrect theories but there are interesting and less interesting ways to view the world." (ibid p6) But as Walsham himself admits, "The literature contains little of substance concerning post-modernism" [in which he seems to include poststructuralism] "and information systems at the time of writing." (ibid. p13) Arguably, in 1993, there was little in the way of confluence between the two fields for Walsham to discover. In the $21^{\text {st }}$ century world of global social networking, however, poststructuralist analysis of information systems is, this paper argues, of substantial interest and significance, and has become a particular project of this author (Kreps 2007; 2009a \& b; Kreps and Pearson 2008).

With respect to this paper's focus on the nature of identity in particular, a number of IS researchers perhaps most famously Roberta Lamb and Rob Kling - have taken part in recent years in a deconstruction of the concept of the 'computer user.' (Lamb \& Kling 2003; Nakamura 2002) Arguably, in the past, IS research all too often fell prey to the accusation, from more sociologically oriented theorists, of 'black boxing' the 'user'. This paper, if not entirely aligned with the movement to "reconceptualize the user as a social actor" (Lamb \& Kling 2003:199), is certainly in a similar vein. As Lamb \& Kling argue, the many theories that shape the common understanding (and influence the design and use) of ICTs, seem to rely largely on notions derived from cognitive social psychology (Fiske and Taylor, 1991), and cybernetic models (Wiener 1946, 1950) that not only omit the social and environmental context (Hayles 1999), but conceptualise the individual in a rather positivistic way.

The 'user' of social networking sites (aside from those created specifically for use within the corporate firewall (DiMicco et al 2008) is not confined to any specific organisational context, and must therefore be conceptualised socially - and therefore sociologically - as being influenced, contextualised, and likely to respond to such a web-based information system in ways quite different from the more usual, limited context of say, a business application within the closed network of an institution or company. The 'user', moreover, is more directly implicated in the case of social networking sites, because it is the user him/herself, in the first instance, that is being represented, in the Personal Profile, through which the networking begins to take place. It is this representation of the 'user', within the information system, that makes it paramount, in any study of social networking sites, to unpack that notion of the 'user.' 
Recent studies around the concept of Internet Psychology, the EU project on Identity in the Information Society, and IFIP workshops on the Future of Identity in the Information Society, have expanded on and brought fresh impetus and a better understanding of the 'user' of the world wide web. Joinson quotes Jourard and Lasakow (1958) on self-disclosure as being "the 'process of making the self known to others"", and based upon studies of computer mediated communication (CMC) in the 1990s concludes that "visually anonymous CMC tends to lead to higher levels of self-disclosure." (Joinson 2007:238). Using a profile on a social networking site in order to meet new people, Joinson suggests "requires a more permissive approach to profile privacy" making the personal profile a "key self-presentation tool." (Joinson 2008:1035) Halperin, (2006) by contrast, makes a crucial distinction between identity, "a set of characteristics which represent a person," and identification, relating to "the disclosure of this identity information," thus recognising the "internal aspect of a person's identity which is entirely his own and on which information technology cannot operate." (Halperin 2006:533).

Both Joinson and Halperin, however, and to an extent DiMicco, and Lamb and Kling, also, seem to perpetuate the somewhat positivistic conception of the nature of the self as a traditional 'Lockean' Individual Subject, after the late $17^{\text {th }}$ century philosopher of the Enlightenment, John Locke. This paper offers by contrast a theoretically informed reading of online personal profiles on social networking sites, such as Facebook, from the perspective of opening up the concept of the 'user' to poststructuralist understandings of the nature of the Self, thus benefiting from developments in the understanding of the human individual during the latter part of the $20^{\text {th }}$ century in sociological and critical theory, specifically in poststructuralism, and the 'decentring of the Individual Subject' (Derrida 1974).

\section{THEORETICAL APPROACHES TO IDENTITY}

Although other theoretical and methodological approaches have much of value to present on the experience of online social networks, contemporary understandings of the nature of the self can bring some especially significant insights which the literature on social networking sites (SNS) seems largely, to date, to be missing. Such understandings have a particular place within the wider philosophical literature. There are perhaps three main foci of the relevant literature on identity - (i) on the nature of identity; (ii) on the nature of societal totality and how it takes part in determining identity; and (iii) on the space between identity and totality. It is the first of these foci that is of main concern in this paper.

The Lockean tradition of the Individual Subject, and the new poststructuralist decentering of the self, both belong to this first group, (i). The Lockean tradition emerges from John Locke (1632-1704), one of the main proponents of British Empiricism - an approach to philosophy and politics influenced by Puritanism but characterised by an enlightened religious toleration (viz the Enlightenment), and of central importance to the American and French revolutions. British Empiricism did for politics what Newton had done for science: just as Aristotle had been replaced by laboratory observation, so the empiricists sought to replace the divine right of kings with a doctrine of the state based on natural principles and scholarly understanding. Locke's influence has been immense, though he does not count amongst the profoundest of philosophers. His is a "piecemeal, tentative, anti-systematic" (Russell 1959:219) approach founded on the predictable behaviour of a new class of individuals that had risen first with the distribution of the wealth of the abbeys and monasteries and thereafter from the proceeds of the sugar and slave trades: the mercantilist class. This class could be relied upon to act with what was known as 'Enlightened self-interest' (Kreps 2007:53) - not exactly calling forth "the noblest sentiments in men" (Russell 1959:219) but at least avoiding the pitfalls of loftier continental European systems and the despots who sought to implement them.

But it is Locke's definition of the Self applying such self-interest that in many ways proved the weakest part of his argument. To elucidate this we must first look at the nature of memory and consciousness. Human consciousness has been the focus of much European philosophy over many centuries. It is understood by most that it usually displays 'unity'. For example when one experiences 
the touch of another, and a feeling of pleasure, one is not conscious of the touch and, separately, of the pleasure. One is conscious of the touch and pleasure simultaneously, as elements of a single conscious experience. This phenomenon is known amongst philosophers as the unity of consciousness (Brook 2006). The diachronic unity of human consciousness, i.e. unified consciousness over time, John Locke and many philosophers since (Brook 2006) have linked to personal identity, i.e., continuing to be a single person across time. However, this definition is fraught with difficulty. Considering the personal identity as a 'subject,' and that the 'subject' of one moment is succeeded by the 'subject' of the next, the (late $18^{\text {th }}$ cent) philosopher Emmanuel Kant's view was that "continuity sufficient to 'retain the thought of the previous subject and so hand it over to the subsequent subject' (1781, A363), continuity sufficient therefore for diachronic unity of consciousness, is quite compatible with the 'retained thoughts' being passed from one subject to another, compatible therefore with an utter absence of personal identity." (Brook 2006). The Lockean tradition of the Individual Subject, therefore, upon which so much of the later $19^{\text {th }}$ century positivist approach of Auguste Comte (Russell 1959:275) to the world of social existence is built, is actually quite shaky ground. As Italo Calvino pointed out, "Memory has to be strong enough to enable us to act without forgetting what we wanted to do, to learn without ceasing to be the same person, but it also has to be weak enough to allow us to keep moving into the future." (Calvino 1981) In contemporary theorising around the nature of memory and consciousness, the notion of this Individual Subject has been questioned, and thus the concept of diachronic unity re-problematised far beyond 'retained thoughts'. Key to that questioning of the notion of the subject, along with Derrida (1974) and other cultural theorists of the poststructuralist movement in philosophical thought (e.g. Michel Foucault 1995), has been a new consideration of the role of power, not just in society as a whole, but in the formation, definition, and self-awareness of the individual. Influence from without, in other words, makes the power of any internal 'Individual Subject' to define the Self highly contingent.

Structuralism - poststructuralism's forerunner - was a fashionable movement amongst French intellectuals in the 1950s and 60s, focussed on the underlying structures inherent in cultural products (such as texts), but seeking rational and scientific results. It used concepts from linguistics, psychology, anthropology and other fields to understand and interpret those structures. It very soon met with internal opposition, however, and evolved quickly into a new approach which continues to be widely used to this day. Poststructuralism, and its contemporary approach to the nature of identity, is the principal philosophical approach propounded in this paper. It shares with Locke an antisystematic, tentative, piecemeal approach, but goes much further than Locke and his contemporaries and descendants, and in many respects quite counter to many of their other assertions, in deconstructing all systems of thought, treating all ideals, systems, structures, definitions and assumptions with suspicion, encouraging, on the contrary, a continual and profound scepticism and freshness and open-mindedness of enquiry as central tenets of its approach. Significantly, a rejection of the Enlightenment Individual Subject is a core tenet.

Derrida, Foucault, Deleuze, Butler and others, some associated with structuralism originally - and even still - others purely a part of the reaction against it, share a number of ideas which hold them together as a 'movement' in philosophical thought. Poststructuralists hold, for example, that the concept of "self" as a separate, singular, and coherent entity - such as the Individual Subject - is a fiction. In literary criticism, the author's meaning is regarded as secondary to the meaning that the reader perceives. Any poststructuralist critique, moreover, must embrace a multifaceted set of interpretations, including the possibility of shifting meaning and movement dependent on perspective. A related poststructuralist approach, deconstruction, aims to espy any binaries, e.g. subject/object, male/female, symbolic/imaginary, rational/emotional, and to contest the normative dominant in such pairs, preferring to show the dependency of the dominant upon the supposedly subservient half of the pair, and through the deconstruction of the assumptions and knowledge systems that set up such binaries show the fluidity between them, how one becomes the other from particular perspectives. This paper includes just such a deconstruction - of Platonism - undertaken by Deleuze. 
Thus the Lockean tradition of the Individual Subject, and the new poststructuralist decentering of the self, in the first group, (i) the 'nature of identity', are in many senses contradictory. Where the Lockean tradition puts forward a stable, continuous individual selfhood, the poststructuralist approach reveals continually shifting ground and differing accents according to perspective.

The other two of the above groupings, (ii) on the nature of societal totality and how it takes part in determining identity; and (iii) on the space between identity and totality, we shall touch on relatively briefly for the sake of clarity. The social construction of the self (Berger \& Luckmann 1967), its presentation in everyday life (Goffman, 1990), and the performative, or 'doing' nature of being, (Butler 1990), have all also contributed to a fundamental shift away from the 'Lockean tradition'.

In the second group (ii), then, focussing on the power of the societal totality to determine identity, Social Constructionism was famously introduced by Berger \& Luckman (1967), as an approach which focuses on the ways in which people and the groups they form contribute to the creation of their perceived social reality - the collective power of society to determine individual identity. Social interaction lies at the heart of all knowledge for the social constructionist. The social shaping of technology, proposed by, among others, Wieber Bijker (1993), belongs to this group, not as a form of technological determinism but in the focus upon how society is shaped by technology which in turn shapes individuals. So too does the work on the postmodern condition by Francois Lyotard (1997), who in his debunking of the grand narratives of society continues this focus on the totality rather than upon the individual. Thomas Kuhn's (1970) analysis of scientific revolutions and the paradigms in between them upheld by the workings of peer review also belongs to this group.

In the third group, (iii), approaches situated in the space in between the individual actor and societal totality, suggest that the formation of individual identity and social reality consists in more than just social interaction. For Actor Network Theorists (ANT), led by Bruno Latour $(1988,1993)$ and John Law (1992) the objects - and in particular the technologies - that societies create, implement and marshal, constitute actors within a heterogeneous network that also includes people, determining by the process of inscription the shape of society, identity, and technologies.

In structuration theory, proposed by Anthony Giddens (1984), an attempt is made to reconcile the issues of whether individuals create society or society determines who we are - to reconcile the two perspectives from the individual / micro level and from the societal / macro level. Giddens does so by disdaining to focus on either the individual actor or societal totality, but instead examining "social practices ordered over space and time" (Giddens 1984:2). This theory acknowledges that all human action is at least partly predetermined within and by the context in which it occurs, but that that predetermination is itself maintained and changed by human action.

\begin{tabular}{|l|l|l|l|}
\hline Focus & $\begin{array}{l}\text { Theoretical } \\
\text { Approach }\end{array}$ & $\begin{array}{l}\text { Principal } \\
\text { author(s) }\end{array}$ & Notion of Identity \\
\hline $\begin{array}{l}\text { (i) Focussed on } \\
\text { Identity }\end{array}$ & Platonism & $\begin{array}{l}\text { Plato, Aristotle, } \\
\text { Locke }\end{array}$ & $\begin{array}{l}\text { Individual Subject true copy of } \\
\text { Ideal 'Higher' Self }\end{array}$ \\
\cline { 2 - 5 } & Poststructuralism & $\begin{array}{l}\text { Nietzsche, } \\
\text { Derrida, Deleuze, } \\
\text { Foucault, Butler }\end{array}$ & $\begin{array}{l}\text { 'self' decentred, always in } \\
\text { question, no 'true' face behind a } \\
\text { series of masks }\end{array}$ \\
\hline $\begin{array}{l}\text { (ii) Focussed on } \\
\text { societal totality }\end{array}$ & $\begin{array}{l}\text { Social } \\
\text { Constructionism }\end{array}$ & $\begin{array}{l}\text { Kuhn, Berger \& } \\
\text { Luckmann, Bijker, } \\
\text { Lyotard }\end{array}$ & $\begin{array}{l}\text { Forces of social conformism } \\
\text { irresistible, all reality is really a } \\
\text { narrative, a discourse rooted in } \\
\text { consensus }\end{array}$ \\
\hline (iii) Focussed & Actor Network & Latour, Law & Human and non-human actors \\
\hline
\end{tabular}




\begin{tabular}{|c|c|c|c|}
\hline \multirow{2}{*}{$\begin{array}{l}\text { on the space } \\
\text { between identity } \\
\text { and societal } \\
\text { totality }\end{array}$} & Theory & & $\begin{array}{l}\text { equal in a network subject to } \\
\text { influence from inscription }\end{array}$ \\
\hline & $\begin{array}{l}\text { Structuration } \\
\text { Theory }\end{array}$ & Giddens & $\begin{array}{l}\text { Focus on social practices ordered } \\
\text { across space and time }\end{array}$ \\
\hline
\end{tabular}

Table 1 - Theoretical Approaches to Identity

To make use of, appreciate, and include the approaches in groups (ii) and (iii), interpretive IS researchers must recognise that the Lockean tradition of group (i) has largely been jettisoned by the later researchers, and that the decentered subject, introduced by poststructuralism, is almost a prerequisite of Social Constructionism, Actor Network, and Structuration Theories. Interpretive researchers, therefore, need to ensure that they are familiar with the new thinking, in order to avoid the pitfalls of the Lockean trap. The Lockean Individual Subject of the positivist tradition, after all, brooks of no influence from outside the self upon the nature of internal identity.

To introduce poststructuralist notions of the self to IS researchers, therefore, in the context of social networking profiles, this paper will begin with an intellectual history of the concepts surrounding representation, most notably the concept of the simulacrum, which will then be used to unpack the concept of the 'user' of social networking sites beyond the mere 'disclosure' of identity information. Though it may be possible to write a full philosophical or intellectual history of the notion of the simulacrum, following the many and varied modifications of the concept, what follows is not an attempt either to achieve or to summarise such a complete history. For the purposes of this paper it suffices merely to summarise the notion of the simulacrum as understood by Plato (1892a-d), and its pivotal role in the Nietzschean project (Nietzsche 1895), taken up by Deleuze (1983, 1990, 1991), to overturn Platonism. Passing mention only will be made of some of the other writers who have contributed to that history of the concept. It is hoped, nonetheless, by touching on the ideas of these thinkers, to familiarise the IS reader with the often thorny issues to be tackled when discussing the nature of representation, and why the representation of self on a social networking website might have so much impact upon our understanding of Self, Other, of Friendship, and of the nature of contemporary information society.

\section{A BRIEF INTELLECTUAL HISTORY OF THE SIMULACRUM}

\subsection{Plato's Cave}

Simulacrum $n$. is defined as an image; a representation, and as an insubstantial, superficial, or vague likeness or semblance, and readers may be familiar with such usage. The Greek philosopher Plato, particularly in Sophist (Plato 1892c) and in Republic, (Plato 1892b), discusses the relationship between the real and the representation, most memorably in the allegory of The Cave. In this allegory, Plato suggests that people are like prisoners chained in a cave, who think the things they see on the wall (shadows) are real and know nothing of their real causes. From this, Plato describes his Theory of Forms: the notion that all manifest reality is but a shadow of an Ideal reality that is its essence, a pre-existing Form upon which the world is based, and is but a copy of (Plato 1892b). In this notion, certain copies are made by those who are truly in touch with the Ideal Form, and whose copies, whilst still merely representations, nonetheless capture the essence of the original Idea, and certain other copies are merely representations, empty and without any true link to the essence of the Ideal original. Thus "copies" or icons (eikones) are well-grounded claimants to the transcendent Idea, and "simulacra" (phantasmata) are like false claimants, built on a dissimilarity and implying an essential perversion or deviation from the Idea. (Plato 1892b). 
Notions of the Self, from this Platonist point of view, therefore, were focussed around being a true claimant, rather than a false one, being 'true' to one's nature in the pre-ordained scheme of things, rather than a pretender to a class not one's own. This view was absorbed and modified by Aristotle and went on to become a central plank of Western philosophy and Christian doctrine for the next two thousand years. With this philosophical background, the nature of mediaeval identity was clear: a unity of self and other, of self and the world; a feeling of belonging and connectedness that brooked of no separation from the whole. The sense of self of mediaeval man was defined by his relation to and above all by his resemblance to everything else around him (Buci-Glucksman 1994). Everything has its place in the god-given order of things, and his only concern is to live up to God's expectations of His Creation, as defined by His priests on Earth.

\subsection{The Inversion of Platonism}

At the end of the nineteenth century, as part of a wider project to overthrow Platonism altogether, to reverse it, Friedrich Nietzsche addressed the concept of the simulacrum in The Twilight of the Idols, (Nietzsche 1895) turning the Platonic definition on its head, and accusing the 'decadent' predominantly Christian philosophers of the previous two millennia of ignoring the reliable input of their senses and resorting to mere constructs of language and reason - a distorted copy of reality. In the twentieth century, Gilles Deleuze $(1983,1995,1990)$, among others, took up Nietzsche's challenge to the future of philosophy, and focussed a good deal of attention on the concept of the simulacrum.

The problem of reversing Platonism, on the face of it, would seem to suggest that the shadows of the cave be given ascendancy over the light of truth, that appearance should triumph over essence, the image over the original. But this is not the inversion that Nietzsche implies, or that Deleuze puts forward. For Deleuze, the inversion of Platonism means the overturning of "both the world of essence and the world of appearance." (Smith 2006:90). To achieve this, Deleuze unpicks Platonism itself: the world of essences and ideal forms exists for Plato only as a means by which to select, to sort, to distinguish, and it is this Platonic operation of sorting that Deleuze focuses upon. The Theory of Forms is proposed by Plato as a means by which to satisfy a more primary motivation to sort out - to faire la difference - between true and false images.

Deleuze approaches Plato's thought - in the style of the intellectual historian - by locating it in Athenian politics - in the agora or public centre that replaces the palace as the centre of Greek city life. The motivation to sort between true and false is thus a historically contingent one, rooted and contextualised in the rivalry of Athenian democracy. Plato's philosophical dialogues reflect the fundamental issue in the Greek city states that derives from their fundamental difference from the imperial states around them: where a monarch, emperor or despot appoints his functionaries, the citizens of a Greek city state must elect from among rival claimants the best man for the job (Plato 1892a; Smith 2006). Deleuze's argument is that in the Theory of Forms, Plato reintroduces the transcendent that was left behind in the (religious) imperial state, but in a new (philosophical) form the Idea. A claimant is well-founded only insofar as he/it resembles or imitates the foundational Idea. "This resemblance is not merely an external correspondence, as the resemblance of one thing with another, but an internal and spiritual... resemblance of the thing to the Idea." (Smith 2006:96) In plain terms, "the aim of Platonism is to deprive nature of the being that is immanent to it, to reduce nature to a pure appearance, and to judge it in relation to a moral Idea that transcends it." (Smith 2006:99).

In the Sophist, (Plato 1892c) Plato reverses the approach of the Statesman (Plato 1892d) and of Phaedrus (Plato 1892b), seeking out not the true, but the false claimant, aiming to define the simulacrum itself. Yet this dialogue reaches a remarkable conclusion: "By dint of inquiring in the direction of the simulacrum," writes Deleuze, "Plato discovers, in the flash of an instant as he leans over its abyss, that the simulacrum is not simply a false copy, but that it calls into question the very notion of the copy... and of the model." (Deleuze 1990:294) The Sophist, for Plato, is the simulacrum 
- and in the end dangerously indistinguishable from Socrates himself - so wily is the cunning of appearances.

Deleuze redefines the simulacrum, wrests it from its lowly Platonic position as that which is furthest from the Idea, the purely negatively conceived false copy, and repositions it as differing from the copy not in degree but in nature. For Deleuze the ability of the simulacrum to lay claim to anything and everything is not what singles it out as a false claimant, but what enables him to create a newly affirmative definition of simulacra. Three characteristics define the Deleuzean simulacrum: firstly, whereas the "copy is an image endowed with resemblance, the simulacrum is an image without resemblance" (Deleuze 1990:257). The reason why Plato so maligned the simulacrum, and which became the thorniest problem of the mediaeval Christian world (Lucifer the fallen angel, closest to God, yet furthest from Him) is that the simulacrum is "beyond good and evil" because it renders them indiscernible - as with Socrates and the Sophist - and thus internalises the difference between them. Secondly, whereas the Platonic copy is true to its foundational Idea by dint of its internal resemblance, the simulacrum is defined by its internal difference or disparity, an internal identity that does not derive from any prior Idea or Form but exists in and of itself within the simulacrum and nowhere else. Thus the concept of uniqueness, of things being in and of themselves, owes everything to the internal disparity of the simulacrum, and resemblance becomes something only evident on the surface of things - a matter of appearance. "Resemblance is always on the exterior, and difference - small or large - occupies the centre of the system." (Deleuze 1995:121). Thirdly, the simulacral enters the region of Pop Art. The multiplication of images, for example in Warhol's Campbell Soup cans, begs the question: which is the originary model?

Once the hierarchy of Idea, copy, false copy has broken down, when there is no original, no first copy, second copy, and so on, no privileged point of view, there are only Masks. Masks were carved or manufactured figures of human or animal or mythical heads, worn by actors in Greek and Roman drama to identify a character or trait (and to amplify the voice). Using this concept of the mask as a metaphor to understand the simulacrum, the Platonic illusion is that a face exists behind the mask, that an originary model sits behind the copy. Escaping such an illusion, the simulacrum, in short, can no longer be said to be a 'false' copy, false in relation to a supposedly 'true' original. The 'mask' is all.

In this way, difference becomes the great Idea. Platonism, although reversed, is at the same time rejuvenated, even completed, and the Platonic project retrieved on a new basis. The old, imperial element of transcendence - the inclusion of which was Plato's error - now jettisoned, the purely immanent theory of Ideas is free to begin with the simulacrum itself. We enter a world in which "Simulacra are those systems in which the different relates to the different by means of difference itself. What is essential is that we find in these systems no prior identity and internal resemblance: it is all a matter of difference" (Deleuze 1990:299). Immanence and internal difference thus become the basic tenets of a pure concept or Idea of difference in a rejuvenated Deleuzean Platonism, whereby difference is no longer a pure quality of things, as with a Platonic Idea, but rather the "reason behind qualities." (Deleuze 1990:57).

\section{$3.3 \quad$ Summary}

To summarise our intellectual history of the simulacrum, then, we may see that the Platonic project of differentiating between rivals, in the athletic democracy of the Greek city state, led him to borrow the concept of transcendence from the surrounding empires, and to bring that transcendence within the field of immanence into a new notion of the Idea. Differentiating between rivals was then a matter of discerning which was a true copy of that Idea, and which had only the appearance and not the internal resemblance of it. Deleuze shows us that it is this very internal difference from the Idea that is characteristic of the simulacrum, which undermines and overturns Platonism, allowing us to escape the transcendent altogether, and bringing us a new great Idea, that difference is the defining concept of immanent reality, and inner uniqueness the truest nature of things - and people - beyond whatever surface resemblance they may have to one another. 


\section{SOCIAL NETWORKING SITES}

Our brief intellectual history complete, then, we must turn back to more familiar ground for the IS researcher, and examine, first, the nature of social networking sites and what other IS researchers have said about them that is of interest to the concerns of this paper. We will then see what impact our foray into poststructuralist thought, and the intellectual history of the simulacrum, may have on our understanding of such sites, and their use.

Since their introduction, social networking sites (SNSs) such as MySpace, Facebook, Bebo, Habbo, and the many, many others have attracted millions of users, many of whom have integrated these sites into their daily lives. These sites allow us to connect or reconnect with people both locally and from all around the world through email, instant messaging, sharing in business or fun exchanges, and video sharing and conferencing. Through these sites we are able to rediscover and talk to old friends from school, connect to existing or potential business contacts, or make new acquaintances in local or farflung places. We are able to build relationships with people in ways that human beings have never before in our history, no longer bound by region, nationality, ethnicity, social role, family, or occupation as to the kinds of companionships we can forge and call our own. This allows us to meet people based on shared interests, political views, or other social activities, or on common language or shared racial or sexuality-based identities (Kreps, 2009b).

These sites offer a range of different technological features, catering to a wide range of interests and practices. While their key technological features are fairly consistent, the cultures that emerge around SNSs are varied. Some, like for example Ecademy or LinkedIn, are specifically professional, others, like MySpace, more centred around music. Bebo, Habbo, ClubPenguin and others are almost exclusively for children or teenagers, and others still, like Facebook, attempt to bring many disparate social groups together in one space.

Whilst there has been a fair amount of scholarship - for example in the Computer-MediatedCommunication (CMC), and Human Computer Interaction (HCI) fields - concerning SNSs, much of it has focussed on the interactions and networking of such sites, and much of the criticism upon the tendency to collect 'friends' in a competitive manner, so devaluing the meaning of friendship to mere cyber-acquaintance. Facebook, interestingly, carries a range of different options through which to identify how one knows someone who wishes to add you as a 'Friend,' including living together, working together, being members of an organisation or club, 'hooking up,' and others. The last of these options reads: "I don't even know this person." Click on it, and Facebook replies - "Then why do you wish to add them?" Facebook "friendliness," however, despite this apparent self-awareness, is no substitute for genuine friendship, according to Professor Ray Pahl, co-author of Rethinking Friendship, (Spencer \& Pahl 2006) and only leaves us feeling dissatisfied. In his opinion, Facebook is a form of immaturity, "It's not a real social network," he says, "it mimics the playground insecurities of primary school kids piling up best friends to find their social niche. When people grow up and settle down, they realise that real friendship isn't about turning on the computer - it requires real effort and taking the rough with the smooth." (Independent 2007)

danah boyd's work on Friendster (boyd 2006) - the one-time pioneer and leading SNS now reduced to a rump of loyal users - has given us an interesting range of viewpoints on the nature and practices of SNSs. She has discussed, among other issues, how the performance of social identity and relationships has shifted the nature of the SNS profile from being "a static representation of self to a communicative body in conversation with the other represented bodies." (boyd 2006) Her focus here is upon communication, and the fact that although "Embodied interaction is taken for granted in everyday communication... mediated conversations require individuals to write themselves into being." It is this "writing themselves into being' which is the focus of this paper, and not the communication or interaction. Nor does this paper address the equally significant issue of how interaction affects the development of identity. "The Friendster Profile," boyd notes, "complete with descriptive data, photographs, articulated friendship links, and testimonials, simultaneously constitutes 
a digital body, a social creation, an initiator of conversation, and a medium for ongoing conversation in multiple modalities." (boyd 2006) This 'digital body' however, and its relationship to its creator, whom it is meant to 'represent', is not problematised in her work. She notes with some enthusiasm that these 'digital bodies' are "public displays of identity where people can explore impression management," referring to the work of Erving Goffman. Impression management includes such elements as "public displays of connection" which "serve as important identity signals that help people navigate the networked social world, in that an extended network may serve to validate identity formation presented in profiles" (Donath and boyd 2004). In the research undertaken by Donath and boyd impression management is explicitly stated as "one of the reasons given by Friendster users for choosing particular friends" (Donath and boyd 2004). boyd notes that "profiles provide an opportunity to craft the intended expression through language, imagery and media," and that the goal is "to look cool and receive peer validation." (boyd 2006) However, the notion of "front' from Goffman's "Presentation of Self in Everyday Life" (Goffman 1990) presupposes not just what one 'gives out' - the intentional display to which boyd likens the personal profile, and the deliberate management of impressions she identifies - but also what one 'gives off' - the unintentional, unconscious clues to one's character that are arguably visible only to those with whom one is interacting face to face.

Scholarship in the IS field has similarly focussed on the 'friendship' issue, and on the nature of networked communication. The main strands of enquiry have focussed upon "the generation of online ties and their integration into the individual's existing social network," on the one hand, and the "role of new communication technologies as a new channel of communication," on the other, (Mesch \& Talmud 2007:585). Livingstone and Helsper's work (2007) offers particularly interesting insight into how issues of anonymity, disclosure of intimate information and exchange of resources affect communication, and it is what goes into a profile and what does not that is of particular importance to the concerns of this paper. Other work in the computer science field has included an extraordinary hoovering up of data from 100,000 social networking site profiles into a semantic map of personal tastes, (Liu et al. 2006).

Further work on identity management in social networking sites has been done by DiMicco and Millen (2007), focussing on a survey of Facebook pages of company employees, and on the shift from use of the profile as a college student to use in the workforce, and how that transition is managed. The survey found that although some users were "managing their self-presentation, crafting their profiles for both a non-professional and professional audience," (DiMicco \& Millen 2007) the majority of their respondents were not. How much this had to do with the 68 profiles studied all being IBM employees is unclear. Their overall conclusions seem largely to concentrate on potential improvements to users' ability to maintain distinctions between different masks:

Outside of social networking sites, bloggers and web professionals often successfully manage multiple online presentations of self, by authoring both a corporate and a personal blog, or maintaining independent web domains with pages for both their professional and personal content. The tools and strategies used by these advanced users can usefully inform the design of emerging multi-community social network applications. (DiMicco 2007:4)

Seldom, it seems, has scholarship addressed the philosophical nature of representing the self online, unpacking the notion of the 'user' of such sites in any real depth. Only, perhaps, Sherry Turkle's seminal work, Life on the Screen: Identity in the Age of the Internet (Turkle 1995) touches on this albeit an "idealistic project of reconfigured and reintegrated postmodern identities on the Internet." (Wiszniewski \& Coyne 2002:195) Perhaps the most interesting recent work, in this respect, for the purposes of this paper, is that of Dorian Wiszniewski and Richard Coyne, in their chapter "Mask and Identity" (Wiszniewski \& Coyne 2002:191), recalling our earlier discussion of the concept of the 'mask' as a metaphor for understanding the simulacrum, replacing the Platonic hierarchy of Idea, copy, false copy. "As the Internet and its successors become more pervasive and the technologies become more sophisticated and convincing," they tell us, "then presumably the issue of identity itself comes under review." (Wiszniewski \& Coyne 2002:191) They take up the issue of Platonism, and of 
the realm of Ideas/Forms as a "place of identity... the immutable part of our human being that participates in the realm of the forms," (Wiszniewski \& Coyne 2002:191) whilst all else is subject to ageing and change. They begin with a critique of the romance of identity in recent IT literature as revealing of such a Platonist grounding, the self or soul being identified with the immutable world of Ideas above and beyond the more tiresome world of the mundane and the physical. Indeed this is a popular interpretation of much cyberpunk fiction: Gibson's characters frequently exhibit contempt for the flesh in preference for a networked virtual identity deemed superior for its lack of substance (Gibson 1993). Making reference to the work of that philosopher of cyberspace, Michael Heim, they suggest that for the techno-romantic, "induction into the digital realm assumes the gravity and significance of the progression to Plato's realm of ideas, as the new real." (Wiszniewski \& Coyne 2002:194)

This brings us to the core of their chapter - the story of the Mask and Identity. Briefly summarised, "the romantic might celebrate the mask as a means of assuming different roles, dressing up, or living out a fantasy," (Wiszniewski \& Coyne 2002:202). This of course is how much of the current IT literature (e.g. Murray 1999, boyd 2006) regards the ability to use avatars and personal profiles. "A conventional, empiricist view of masking," Wiszniewski and Coyne continue, "would recognize that, outside the false imagery of the carnival, our experience is also fraught with exposure to superficialities - custom and prejudice," (Wiszniewski \& Coyne 2002:202). But for both the romantic and the empiricist, the face behind the mask remains the true object. "For critical theory, the mask is constituted by all the ruses of the capitalist system to conceal the hegemony of oppression. More perniciously, the mask conceals the fact that there is a mask." (Wiszniewski \& Coyne 2002:203). For the phenomenologist, the mask and what lie behind it are both subject to the same context, and must be understood within that light. But to the radical, Deleuzean eye, the 'essential' behind the mask is shown to also be a mask: there is, in fact, in place of the Platonic hierarchy of Idea, copy, false copy etc, a whole series of masks, each referring back to another influence, to a further context, beyond which there is no final fixed referent, no 'authentic' face. "This is tantamount to asserting that there is nothing behind the mask, there is everything behind the mask, or the mask is everything." (Wiszniewski \& Coyne 2002:203). In the end, identity, under these conditions, is always in question, and cannot be discussed as a static idea. Difference, as we have seen in the earlier discussion, and the continuous change that it implies, is the "central dynamic that conditions identity," and so identity is always a question, and never an answer (Wiszniewski \& Coyne 2002:204).

\section{COPIES, RESEMBLANCE, SIMULACRA AND MASKS}

\subsection{Analysis}

The SNS Profile, in the light of our discussions concerning the simulacrum, the mask as metaphor for a more Deleuzian understanding of the simulacrum, and the nature of identity, turns out to be very revealing. From a Platonic perspective, one might view the SNS profile as at best a poor, virtual, second copy of the first copy of one's essential, Ideal Self. When seeking new 'Friends' on the social network, after gaining temporary access to the full profile (e.g. via the 'Facebook Poke') one might scan the contents of the profile in an attempt to discern whether the information conveyed by it constituted a trustworthy copy that truly resembled its creator, or a false copy, a simulacrum that revealed nothing of the true individual behind it. Judgement on whether to approve 'Friending' might then be based upon whether we deem the profile a true representation or not. Certainly in the case of Bebo, Habbo and other more teen and child oriented social networks and the predatory threat of grooming from much older cyber-stalkers, this judgement carries great responsibility and needs to be, to a certain extent, policed by the social network itself, through proofs of identity as part of the initial registration process. But in the case of Facebook, the 'culture' of this social network is to present oneself, with one's full real name, to those whom one already knows, in networks already established in real life. One adds additional, new 'friends' on the social networking site itself only through 
recommendation via pre-existing networks, or through chosen channels such as the befriending applications that have proliferated to facilitate chance meetings. The professionals' social networking site LinkedIn applies this approach even more rigorously. The Facebook profile in particular is required to achieve several things at once - and to several different potential audiences, both known and unknown - rendering its representative burden extremely complex (see DiMicco and Millen 2007).

But from the Deleuzean perspective, the SNS profile understood as a simulacral mask worn by its creator in the virtual world of computer mediated communication, hides no essential, Ideal self more authentic than the mask. The profile is but one of its creator's many masks, and the representative burden lifts, becomes more playful, and perhaps even more revealing. Indeed we might go so far as to suggest that the continuously changing nature of the profile - through the news feed and new applications - is revealing of the differential nature of the identity/question that created it - and defines the profile as a 'digital body' (boyd 2006) with a life of its own. Yet perhaps rather than merely a rich seam "for scholars investigating processes of impression management, self-presentation, and friendship performance," (boyd 2007) these digital bodies/masks might better be understood as public identities/questions, being continually co-created with the medium, through which we can explore new modes of being. Again, identity is always a question, and never an answer (Wiszniewski \& Coyne 2002:206). Individuals, moreover, frequently maintain a number of differing profiles on a number of different social networking sites (Szomszor et al 2008).

Certainly the phenomenological constraints of the context within which the profile is situated - the features and applications provided by MySpace, Facebook et al - narrow what the mask can display. If "mediated conversations require individuals to write themselves into being" (boyd 2006) then the tools available prescribe the range of what one can be in this medium - presenting for us a figure of the phenomenological constraints our identities are placed under within the socio-political context of the networked society within which such profiles are made possible. It is also clear that the romantic notions of the virtual profile gaining us freedom in the cyberspatial world from the perils and tribulations of the mundane are as illusory as the shadows of the allegorical Cave.

The Facebook profile, in particular, bringing together the masks of professionalism, of family, of social group, school friends, college acquaintances and net-friends, constitutes not one, but a 'soup' of masks that interrelate and occasionally clash - 'giving off' more than we would sometimes wish (Goffman 1990). From the Platonic perspective, these clashes can cause us to rush headlong for the delete button on the latest post from the friend who knows things about us we would not wish other friends or work colleagues to know. This soup of masks exposes our careful ploys - the identities we try to present in different contexts and at different times - and thus foregrounds the chain of reference, the endless cycle of masks with no fixed final referent, which we have seen through Deleuze's eyes. More perhaps, than any other more specialised and less populous SNS, Facebook brings us face-toface with the multiplicity of our own natures, and begs the question - who are we?

An SNS profile, we can say, therefore, as a result of the discussions in this paper, is neither copy, nor resemblance of any essential self 'I' might identify as 'me'; an SNS profile is a simulacrum, a mask in its own right combining many others, defined by its internal difference from the person it is supposed to represent - the person who is always someone different according to whichever context $\mathrm{s} / \mathrm{he}$ is in, and never all of them at once, or in any sense 'essentially' one of them rather than any other.

$$
\text { Implications }
$$

Moving beyond our focus upon identity into the social sphere, and considering, by way of recommendations for further work, the impact of the notions discussed in this paper upon our understanding of how interaction affects the development of identity, it is clear that the nature of SNS makes it potentially a very strong influence upon such identity formation. 
As a paper at the recent IFIP Workshop on the Future of Identity in the Information Society pointed out, "Communities are affected by the individual identities of their population but likewise those communities also provide information to allow the formation of personal identities." (Anderson 2007) In small rural or village communities, and in respect of children, teenagers and young adults in the formative phases of life, this is of particular importance, as whether our definitions of identity are Platonically essentialist or straddle Deleuzean multiplicities the effect upon each other is the same: individuals affect the formation of each others' personal identities. This is almost a given in much contemporary sociological literature (e.g. Goffman 1990), despite the continued adherence of so many IS researchers to the Lockean tradition. In the Information Society, where arguably, in comparison to more traditional communities, we are experiencing "the devaluing of any human 'knowledge' or 'experience' that cannot be reduced to digital impulses," and, worse, a form of "retreat into cyberspace," (Anderson 2007) that effect upon one another takes on new, mediated forms. In our Information Age "a direct pathway to individuals has been established" Anderson reminds us, "which bypasses geographic community networks and traditional forms of identity formation." (Anderson 2007) We might say that, as seen above, Facebook in particular transcends temporal networks as well as physical ones, rendering friendsreunited obsolete as soon as it opened up to the wider adult population. Friendsreunited, now owned by ITV, relaunched in April 2008 without its former "pay walls' (a subscription formula sites such as MySpace and Facebook never adopted) in an attempt to remain relevant, and is largely now aimed at an older market (White 2008).

SNSs therefore present us with a mediated influence upon identity formation which, this paper would argue, foregrounds and emphasises the Deleuzean multiplicity of our Selves, and contributes to an understanding by its users that each of us wears any number of masks according to the context we find ourselves in. Less positively, however, it does so often by pooling together in a single virtual space the most superficial of details from each of those masks, and thereby contributing to the magpie-like "friend collecting" behaviour so often written about by other commentators (boyd \& Heer, 2006, boyd 2006, Livingstone \& Helsper 2007, Mesch \& Talmud 2007). Only through the email and instant messaging system incorporated into most SNSs, perhaps, does some semblance of traditional correspondence live on whilst the vast majority of traffic seems to be about Vampires biting each other, virtual and therefore conspicuously dry water fights, people 'poking' one another, and the sending of pixellated clipart masquerading as gifts.

\section{CONCLUSION}

In summary then, after setting out the theoretical context on the nature of identity from Lockean and poststructuralist perspectives, we have delved into an intellectual history of the notion of the simulacrum, as understood by Plato (1892a-d), and in its pivotal role in the Nietzschean project (Nietzsche 1895), taken up by Deleuze $(1983,1990,1991)$, to overturn Platonism. Through thus familiarising the IS reader with some of the issues to be tackled when discussing the nature of representation, we have seen that the representation of self / user on a social networking website has a good deal of impact upon our understanding of Self, Other, of Friendship, and of the nature of contemporary information society.

For interpretive IS research, the implications are profound. No longer can the positivistic, Lockean conception of the 'user' as Individual Subject making decisions based upon 'enlightened self-interest' go unchallenged. Usability and adoption theories need to be revisited and reconceived. For the interpretive IS researcher, armed now with newly unpacked concepts of the user of social networking sites, a whole range of new survey questions and lines of enquiry opens up, with the promise of some extremely revealing results. The fluidity of identity-as-question revealed by the simulacral understanding of online personal profiles in this paper implies a much greater uncertainty of reaction from users to modifications in information systems affecting user interaction. On the one hand the improbable becomes more likely, the probable less reliable - outcomes borne out by the rapidly changing history of online social networking over the last several years: who, after all, in 2000, would 
have thought that the massive popularity of FriendsRenunited would be so completely eclipsed only a few years later by the likes of MySpace and Facebook? (White 2008) On the other hand, the internal rules of a popular site become more easily assimilated by users for whom their presence on any site is but one of many 'masks'. The huge differences between MySpace and Facebook do not preclude vast numbers of people having profiles on both sites - and using both regularly.

For advertising supported businesses, user-generated-content driven websites such as social networking sites are not in fact, in the light of the concepts addressed in this paper, as reliable indicators of user preferences as some marketers might wish; user preferences, in fact, are not what they may seem; indeed the implication is that demand may be more closely generated by supply, and perhaps in the SNS context even more than elsewhere. The reliability of marketing hype activities leading to the creation of a supportive market environment may in fact have more power than previously or otherwise granted it - which perhaps marketers may be pleased to know, and of which perhaps venture capitalist investors in SNS are already aware (Kreps and Pearson, 2008).

It is perhaps in the very cornerstone of Deleuze's argument against Plato, that in the Theory of Forms the democratic revolution was reined in once more by the notion of the transcendent, whose imperial forms it had only just escaped, that we might find renewed enthusiasm for the revolutionary power of the internet, and of the world wide web. Deleuze's simulacrum presents us with a concept that values difference and uniqueness above all else, albeit that our notions of the individual self become thereby more fluid, more contingent, more contextual - less 'centred'. Deleuze talks of systems in which the different relates to the different by means of difference itself, and perhaps the most fundamental implication of this core philosophical realisation for IS designers is that the monolithic, unified information system that so many companies try to create and which so often fails to live up to expectations, does so because it is based upon a positivistic, Lockean understanding of the user, and a positivistic faith in the efficacy of such systems. On the contrary, it would seem, disparate, interoperable systems that incorporate difference, context, and contingency into a looser, more flexible, fluidity of approach - such as user-generated-content systems like social networks - not only achieve greater buy-in from users but have greater chance of success (Kreps \& Richardson 2007).

Finally, of greatest significance for the wider IS research community, this paper has provided insight into the next step for interpretivism in information systems: dispensing with the Lockean tradition in its understanding of the 'user', and addressing the issues of the decentering of the Individual Subject upon which Social Constructionism, Actor Network, and Structuration Theory all in part depend. This paper urges the IS community to embrace poststructuralist thought. Understanding the simulacral uniqueness of the individual, and the contingent nature of whichever mask that individual may be wearing when using an information system, will provide invaluable additional insight into usability studies and the design of organisational systems, let alone social systems, particularly in an age when social systems are becoming increasingly a part of the workplace. Although new and radical the philosophical approach of this paper nonetheless stands on Walsham's (1993) shoulders, and constitutes, in part, a call to arms for IS researchers to study and benefit from the poststructuralist understanding not only of the Self, but of the societal totality of which we are all a part. 


\section{References}

ANON (2007) Facebook Scares Me The Independent on Sunday, Independent News and Media 26 Aug.

ANDERSON K. (2007) The Absent Identity: Community isolation in an age of information overload. In Proceedings of the Third International Summer School organized by IFIP WG 9.2, 9.6/11.7, 11.6 The Future of Identity in the Information Society (FISCHER-HUBNER, S, DUQUENOY, P, ZUCCATO, A, MARTUCCI, L Eds) Springer, New York

BERGER P and LUCKMAN T (1967) The social construction of reality. Penguin, Harmondsworth BIJKER W and Law j (1992) Shaping Technology, Building Society. MIT Press, Massechusetts. boyd d and ELLISON N (2007) Social Network Sites: Definition, History, and Scholarship. Journal of Computer Mediated Communication 13(1), 210-230

boyd, d \& Heer, J. (2006) Profiles as Conversation: Networked Identity Performance on Friendster. In Proceedings of the Annual Hawaii International Conference on System Sciences 59c 3 boyd, d. (2006) Identity Production in a Networked Culture: Why Youth Heart MySpace. MacArthur Foundation Series on Digital Learning - Youth, Identity, and Digital Media Volume (ed. David Buckingham). Cambridge, MA: MIT Press, pp. 119-142

BROOK A and RAYMONT P (2006) The Unity of Consciousness. Stanford Encyclopedia of Philosophy, http://plato.stanford.edu/entries/consciousness-unity/ [accessed 20/5/09] BUCI-GLUCKSMAN C (1994) Baroque Reason. Sage, London BUTLER J (1990) Gender Trouble. London, Routledge.

CALVINO I (1981) If On A Winter's Night a Traveller. Harcourt Brace, Florida, US

DELEUZE G (1983) Plato and the Simulacrum. Tr Krauss, R. October 27, 45-56.

DELEUZE G (1990) Logic of Sense. tr. Lester, M. \& Stivale, C. Columbia Uni Press. New York. DELEUZE G (1995) Difference and Repetition. Tr Patton, P. Uni of Columbia Press. London. DERRIDA J (1974) On Grammatology. tr. Spivak G. C. John Hopkins University Press. Baltimore. DIMICCO J, MILLEN D, GEYER W, DUGAN C, BROWNHOLTZ B, and MULLER M (2008) Motivations for Social Networking at Work. In Proceedings of CSCW: 2008 ACM Conference on computer supported cooperative work 711-720

DIMICCO J and MILLEN D (2007) Identity Management: Multiple Presentations of Self in Facebook. In Proceedings of International ACM Siggroup Conference On Supporting Group Work 383-386

DONATH J and boyd d (2004) Public displays of connection. BT Technology Journal 22 (4), 71-82 FISKE S and TAYLOR S (1991) Social Cognition. New York: McGraw-Hill, Inc.

FOUCAULT M (1995) The Order of Things. Routledge

GIBSON W (1993) Neuromancer. Harper Collins. London.

GIDDENS A (1984) The Constitution of Society: Outline of the Theory of Structuration. University of California Press

GOFFMAN E (1990) The Presentation of Self in Everyday Life. Penguin. London. 
HALPERIN R. (2006) Identity as an Emerging Field of Study. FIDIS Datenschutz und Datensicherheit 30(9), 533-537

HAYLES N (1999) How We Became Postmodern. Chicago, University of Chicago Press.

JOINSON A (2008) 'Looking at', 'Looking up' or 'Keeping up with' people? Motives and Uses of Facebook. In Proceedings of the 26th Annual SIGCHI Conference on Human Factors in Computing Systems ACM, New York, (pp. 1027-1036).

JOINSON A and PAINE C (2007) Self-Disclosure, Privacy and the Internet. In Oxford Handbook of Internet Psychology (JOINSON A, McKENNA K, POSTMES T and REIPS U-D, Eds) pp 237-252, Oxford University Press, England.

JOURARD S and LASAKOW P (1958) Some factors in self-disclosure. Journal of Abnormal and Social Psychology 56(1), 91-98.

KLEIN H and MYERS M (1999) A Set of Principles for Conducting and Evaluating Interpretive Field Studies in Information Systems. MIS Quarterly 23(1), 67-93.

KREPS D and PEARSON E (2009a) Community as Commodity: Social networking and transnational capitalism. In Virtual Social Networks: Mediated, Massive and Multiplayer sites (PANTELI N Ed.) pp155-174 Palgrave London, UK.

KREPS D (2009b) Performing the Discourse of Sexuality Online: Foucault, Butler, and Video-sharing on Sexual Social Networking Sites, in: Proceedings of the Fifteenth Americas Conference on Information Systems, San Francisco, California August 6th-9th 2009, AMCIS, San Francisco, USA, pp.1-8.

KREPS D (2008) Virtuality: Time, Space, Consciousness and a Second Life. In Exploring Virtuality: Social, Global and Local Dimensions (PANTELI N and CHIASSON M, Eds.) pp254-268 Palgrave, London, UK.

KREPS D and RICHARDSON H (2007) IS Success and Failure: The Problem of Scale. Political Quarterly 78(3), 439 - 446

KREPS D (2007) Cyborgs: Cyborgism, Performance and Society. Lulu.com KUHN TS (1970) The Structure of Scientific Revolutions. Chicago, University of Chicago Press. LAMB R and KLING R (2003) Reconceptualizing Users as Social Actors. MISQ. 27(2) 197-235 LATOUR B (1988) Science in Action: How to Follow Scientists and Engineers Through Society Harvard University Press.

LATOUR B (1993) We Have Never Been Modern Harvard University Press.

LAW J (1992) Notes on the Theory of the Actor-Network: Ordering, Strategy and Heterogeneity Systems Practice 5, 379-393.

LIU H, MAES P and DAVENPORT G (2006) Unraveling the Taste Fabric of Social Networks International Journal on Semantic Web and Information Systems 2(1), 42-71

LIVINGSTONE S and HELSPER E (2007) Taking risks when communicating on the Internet: the role of offline social-psychological factors in young people's vulnerability to online risks Information, Communication \& Society 10(5), 619-644

LYORTARD F (1997) The Postmodern Condition Manchester University Press, Manchester, UK. 
MESCH G and TALMUD I (2007) Editorial Comment: e-Relationships - the blurring and reconfiguration of offline and online social boundaries Information, Communication \& Society, 10(5), $585-589$

MURRAY J (1999) Hamlet on the Holodeck - the future of narrative in cyberspace. MIT Press. Cambridge

NAKAMURA L (2002) Cybertypes: Race, Ethnicity, and Identity on the Internet. Routledge. London. NIETZSCHE F (2008) Twilight of the Idols. Oxford Paperbacks PLATO (1892a) Phaedrus. In The Dialogues of Plato (JOWETT B tr.) Oxford University Press. PLATO (1892b) Republic. In The Dialogues of Plato (JOWETT B tr.) Oxford University Press. PLATO (1892c) Sophist. In The Dialogues of Plato (JOWETT B tr.) Oxford University Press. PLATO (1892d) Statesman. In The Dialogues of Plato (JOWETT B tr.) Oxford University Press. RENNINGER K amd SHUMAR W (Eds.) (2005) Building Virtual Communities. Cambridge Uni Press.

RUSSELL B (1959) Wisdom of the West. Rathbone Books, London.

SMITH D (2006) The concept of the simulacrum: Deleuze and the overturning of Platonism. Continental Philosophy Review, 3, 89-123.

SPENCER L and PAHL R. (2006) Rethinking Friendship: Hidden Solidarities Today. Princeton Uni Press.

STAMPER R, LIU K, HAFKAMP M and ADES Y (2000) Understanding the roles of signs and norms in organizations - a semiotic approach to information systems design. Behaviour \& Information Technology, 19(1), 15-27

SZOMSZOR M, CANTADOR I and ALANI H (2008) Correlating user profiles from multiple folksonomies. In Proceedings of the Nineteenth ACM Conference on Hypertext and Hypermedia ACM, New York, NY, 33-42

TURKLE S (1995) Life on the Screen: Identity in the Age of the Internet. Simon \& Schuster. London WALSHAM G (1993) Interpreting Information Systems in Organisations. John Wiley. Chichester. WALSHAM G (1995) The Emergence of Interpretivism in IS Research. Information Systems Research 6(4), 376-394.

WHITE D (2008) ITV to relaunch Friends Reunited. Telegraph Newspaper 23 Mar. WIENER P (Ed.) (1974) The Dictionary of the History of Ideas: Studies of Selected Pivotal Ideas. Charles Scribner's Sons, New York.

WIENER N (1946) Cybernetics : or control and communication in the animal and the machine. John Wiley \& Sons, London, UK.

WIENER N (1950) The human use of human beings: cybernetics and society. Eyre and Spottiswoode, London, UK

WISZNIEWSKI D and COYNE R (2002). Mask and Identity: The Hermeneutics of Self Construction in the Information Age. In Building Virtual Communities: Learning and Change in Cyberspace. (RENNINGER A and SHUMAR W Eds.) pp191-214 Cambridge. Cambridge University Press, UK. 
Dr David Kreps is an 'early adopter', pioneering thinker and commentator, with a fascination for technology and its impact upon society. A web developer since 1995, following his career as a Local Authority Arts Centre Director, he did his PhD thesis on Cyborgism, and since completing it in 2003 has become an expert on Web Accessibility, and explorer into the philosophy of Virtuality. He is Vice-Chair of the IFIP Working Group 9.5 on Virtuality and Society, and has published widely in Information Systems journals and conferences on eAccessibility and Virtuality. d.g.kreps@salford.ac.uk

danah boyd likes her name to be printed without capitals. 